\title{
The Role of Intraoperative Cytology in the Diagnostic Evaluation of Ovarian Neoplasms
}

\author{
Mohammad Shahid Sufian Zaheer Aysha Mubeen Khaliqur Rahman \\ Rana K. Sherwani \\ Department of Pathology, Jawaharlal Nehru Medical College, Aligarh Muslim University, Aligarh, India
}

\author{
Key Words \\ Cytological smears · Frozen sections · Histopathology • \\ Intraoperative cytology $\cdot$ Ovarian neoplasms
}

\begin{abstract}
Objective: To determine the role of intraoperative cytology (IOC) in the diagnostic evaluation of ovarian neoplasms. Methods: The present study was conducted in the Department of Pathology, Jawaharlal Nehru Medical College, AMU, Aligarh, India, over a time span of 18 months. Depending on the consistency of the lesion, touch, scrape or crush techniques were used to prepare cytological smears. Smears were fixed in 95\% ethyl alcohol and then stained with hematoxylin and eosin or Papanicolaou stains. Cytological results were compared with the histological diagnosis taking the latter as the gold standard. Results: Of 50 lesions studied by IOC, 25 lesions were labeled as benign, 24 lesions as malignant and 1 lesion was inconclusive. Final histological diagnoses labeled 25 lesions as benign and 25 lesions as malignant. Comparing the diagnosis of cytology smears with histology sections, 47 of 50 cases were concordant. Sensitivity, specificity and diagnostic accuracy were $95.8,96.0$ and $95.8 \%$, respectively. Conclusions: IOC is a good complement to histopathology in the study of ovarian neoplasms, particularly in
\end{abstract}

developing countries like ours, where the facility of frozen sections is often not available, since a rapid preliminary diagnosis may help in surgical management planning.

Copyright $\odot 2012$ S. Karger AG, Base

\section{Introduction}

Intraoperative cytology (IOC) is a method of intraoperative consultation with the help of cytology smears. Traditionally, frozen sections are employed for intraoperative pathological evaluation. In 1927, Dudgeon and Patrick [1] introduced cytology as the method of intraoperative pathological evaluation. Since then, several reports have attested the accuracy of IOC evaluation of tissues removed from several organs [2-6].

The most important indication for IOC is to establish or confirm diagnosis rapidly. In the study by Mair et al. [4] , average time required for IOC was only $2 \mathrm{~min}$, whereas frozen sections take $10 \mathrm{~min}$; the same processes took 13 and $25 \mathrm{~min}$, respectively, in the study by Eltabbakh and Trask [7] in 2000. Other advantages of IOC are its simple, inexpensive, excellent preservation of cellular details, with no loss of tissue as occurs with cryostat sections, and adequacy of surgical margins.

\section{KARGER}

Fax +4161306 1234

E-Mail karger@karger.ch

www.karger.com
C 2012 S. Karger AG, Basel

0001-5547/12/0565-0467\$38.00/0

Accessible online at:

www.karger.com/acy
Correspondence to: Dr. Mohammad Shahid

Department of Pathology, Jawaharlal Nehru Medical College, AMU

C-1 Azra Garden, Nagla Road

Dodhpur, Aligarh, UP 202002 (India)

Tel. +91 812697 4063, E-Mail shahidaftab@gmail.com 
IOC has not been broadly included in the diagnosis of ovarian tumors and there are only few reports on the diagnosis of ovarian tumors by IOC. The diagnosis of ovarian neoplasms is mainly based on histopathological examination because of the simple reason that ovaries are inaccessible for cytological techniques except when approached by imaging techniques. Fine-needle aspiration cytology in the preoperative investigation of ovarian tumors has been discouraged since puncture of a cystic carcinoma might cause intraperitoneal seeding, but IOC enables a rapid diagnosis without fear of dissemination of ovarian cancer.

The main objective of our study was to evaluate the accuracy of IOC diagnoses of ovarian tumors compared with histopathology diagnoses, since histopathology is the gold standard in the diagnosis of ovarian cancers.

\section{Materials and Methods}

The present study was conducted in the Department of Pathology, Jawaharlal Nehru Medical College Hospital, Aligarh Muslim University, Aligarh, during a time span of 18 months (March 2006 to August 2007). For each case, clinical, laboratory and radiological data were collected. Grossly solid tumors/solid-cystic neoplasms were included in the study. Depending on the consistency of the lesion, touch, scrape or crush techniques were used to prepare cytological smears. Touch or imprint was the most common technique used, where a clean glass slide was touched to a freshly cut raw lesion surface. Scrape smears were prepared by scraping the surface with the edge of a glass slide and then smearing it gently over another clean, sterilized glass slide surface. This technique was preferred for the lesions having somewhat harder consistency. The crush technique was used for lesions that were friable or necrotic. A small bit of the tissue was crushed and smeared gently between two clean glass slide surfaces.

Smears thus prepared were fixed in $95 \%$ ethanol and stained rapidly with hematoxylin and eosin ( $\mathrm{H} \& \mathrm{E})$. The slides were immediately dipped in hematoxylin for $1 \mathrm{~min}$, rinsed rapidly with distilled water, differentiated with ammonium hydroxide, counterstained with eosin by three slow dips, washed in tap water, dried, mounted in a mixture of distyrene (a polystyrene), a plasticiser (tricresyl phosphate), and xylene and covered with a coverslip. The entire process takes $2 \mathrm{~min}$ and $23 \mathrm{~s}$. This was a modification of a previously used technique [6], which is applied at our cytopathology laboratory. We have also compared it with routine $\mathrm{H} \& \mathrm{E}$ staining. Special stains (periodic acid-Schiff and Alcian blue) were used in difficult cases to demonstrate mucin.

The remaining tissue was immediately fixed in formalin and processed for paraffin blocks. Histological diagnosis of paraffinembedded tissue is considered the gold standard for statistical evaluation of cytological diagnosis.

For statistical purposes, all malignant lesions and borderline ovarian tumors were taken as a positive control and all benign lesions were taken as a negative control. Cytology- and histologypositive cases were labeled true positive, histology-positive and cytology-negative cases were labeled as false negative, histology- and cytology-negative cases were labeled as true negative and histology-negative and cytology-positive cases were labeled as false positive. Paucicellular cases, where no opinion was possible, were labeled as inconclusive. Sensitivity, specificity and diagnostic accuracy was calculated using descriptive statistics.

\section{Results}

The total number of ovarian tumors studied was 50 , and age ranged from 14 to 68 years. Out of these 50 tumors, 25 (50\%) were benign, 5 (10\%) borderline and 20 (40\%) malignant. Serous tumors were the most common $(\mathrm{n}=24,40 \%)$ followed by mucinous tumors $(\mathrm{n}=10,20 \%)$ and germ cell tumors $(n=10,20 \%)$. The scrape technique was found to be the best method for preparing the smears. Cellularity was high compared to other techniques and morphological preservation was also better.

Rapid $\mathrm{H} \& \mathrm{E}$ staining was found at par in quality with the routine technique. It took only $2 \mathrm{~min}$ and $23 \mathrm{~s}$ and was able to show good cytoplasmic nuclear differentiation as well as matrix material.

Smears from 14 benign serous tumors presented papillary clusters of epithelial cells with small dark, bland nuclei in small groups as well in an isolated background containing blood with some cystic macrophages (fig. 1). There were 6 cases of benign mucinous tumors showing tall columnar cells with basally placed nuclei and emptylooking cytoplasm in a highly viscous mucinous background (fig. 2).

Smears from 3 borderline serous tumors were papillaroid in structure and accumulated in clusters of low columnar cells. The number of cells in such clusters varied, ranging from a few to several hundreds. Nuclear abnormalities were relatively inconspicuous and nucleoli were small. Histopathological sections revealed a papillary structure lined by low columnar to cuboidal cells with multilayering and some atypical changes. No invasive component was noted. Smears from 2 borderline mucinous tumors demonstrated cohesive sheets with moderately atypical mucin-secreting columnar cells and evidence of multilayering. Histology revealed a filiform papillary structure with nuclear stratification and some atypia with abundant apical mucin. No evidence of invasion was noted.

There were 7 cases of serous cystadenocarcinoma showing columnar cells with a high $\mathrm{N}$ :C ratio forming papillary and glandular aggregates in a turbid background along with many single cells and syncytial aggregates. The tumor cell generally had a small-to-moderate amount of cyanophilic cytoplasm, possibly with vacuola- 


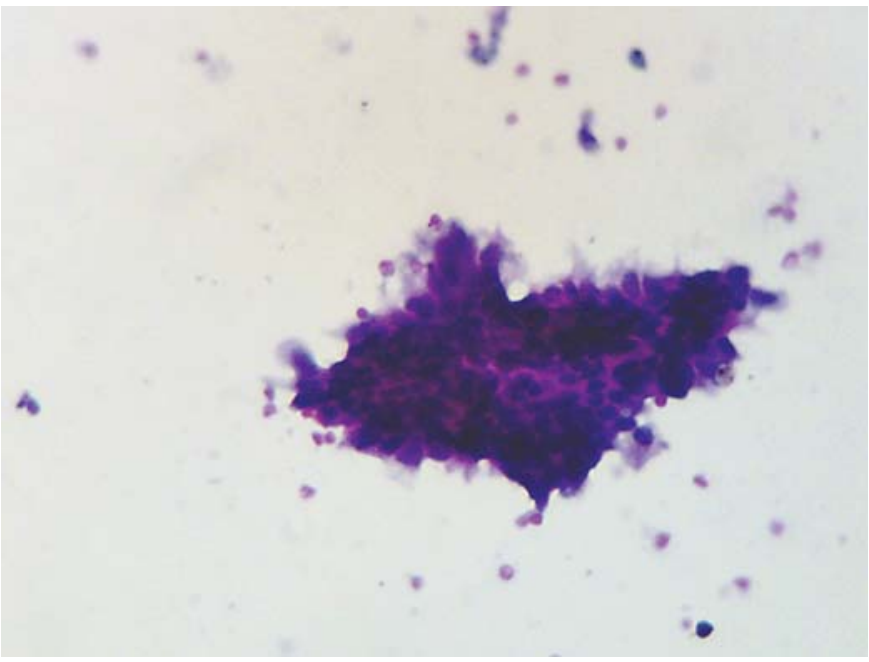

Fig. 1. Serous cystadenoma: imprint smear shows aggregates of epithelial cells with columnar shape and dark bland nucleus forming a papillaroid fragment in a background containing blood and macrophages $(\mathrm{H} \& \mathrm{E}, \times 40)$.

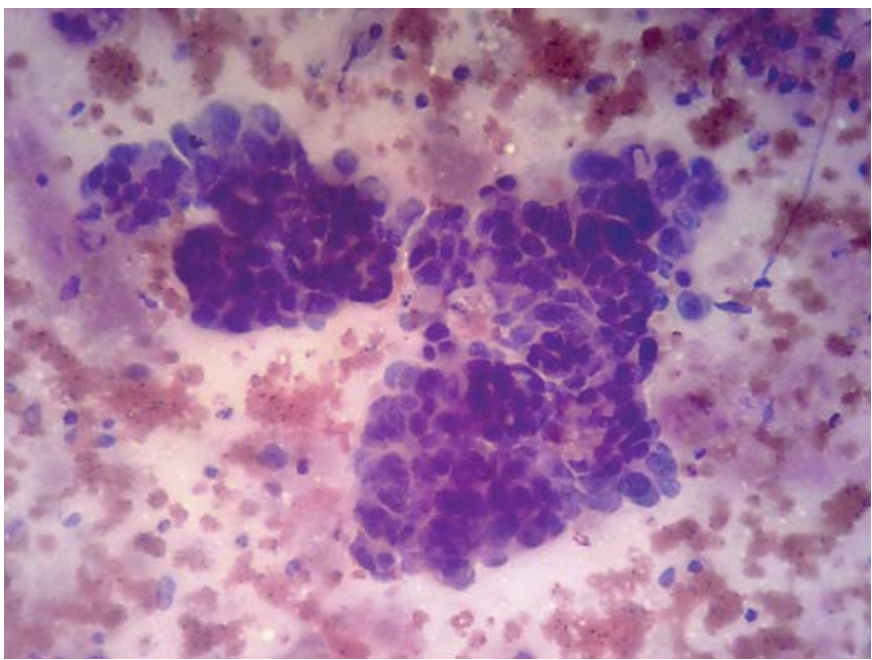

Fig. 3. Serous cystadenocarcinoma: imprint smear shows columnar cells with high $\mathrm{N}$ :C ratio forming papillary and glandular aggregates in a turbid background along with many single cells. The tumor cell generally has a small-to-moderate amount of cyanophilic cytoplasm $(\mathrm{H} \& \mathrm{E}, \times 40)$.

tion. Psammoma - when present - were always a helpful finding (fig. 3). Three smears showed mucinous cystadenocarcinoma with a highly viscous mucinous background containing cohesive sheets and aggregates of tall columnar mucin-secreting cells with nuclear indication of malignancy (fig. 4).

Intraoperative Cytology in Ovarian Neoplasms

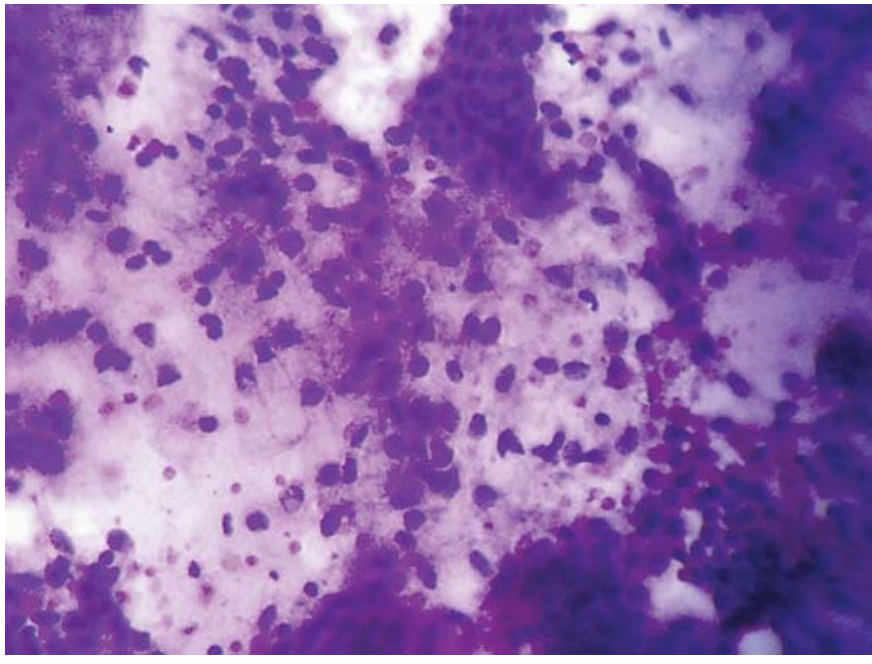

Fig. 2. Mucinous cystadenoma: imprint smear shows a highly viscous mucinous background containing epithelial cells with columnar shape with basally placed nucleus and empty-looking cytoplasm containing mucin $(\mathrm{H} \& \mathrm{E}, \times 40)$.

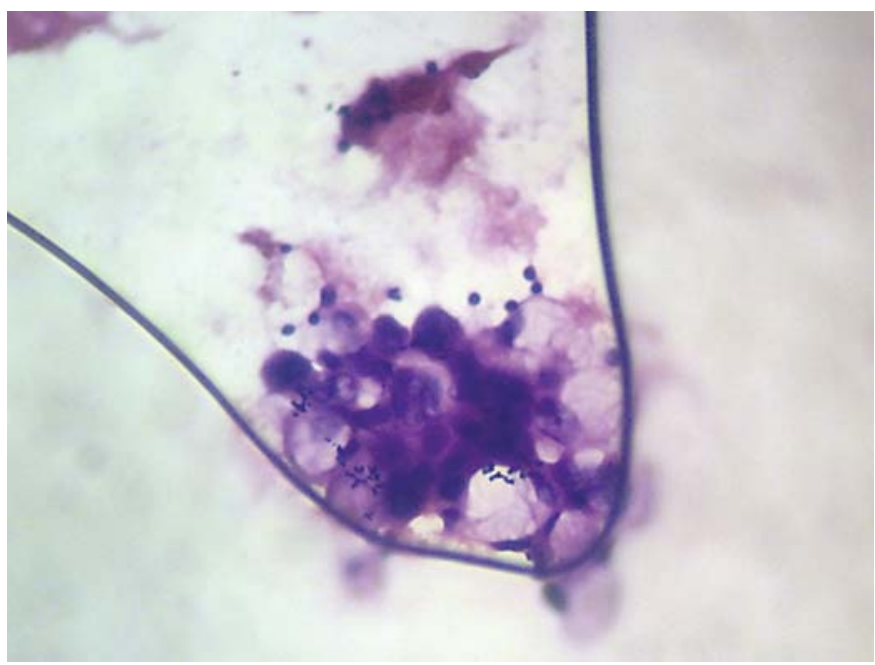

Fig. 4. Mucinous cystadenocarcinoma: imprint smear shows a mucinous background containing cells with pleomorphic nuclei, increased $\mathrm{N}: \mathrm{C}$ ratio, coarse chromatin and eccentric-placed nucleus with cytoplasm containing mucin ( $\mathrm{H} \& \mathrm{E}, \times 40)$.

There were 2 cases of endometrioid carcinoma with cytological criteria of malignancy. Cells had eosinophilic granular cytoplasm and micoglandular and cribriform patterns. Absence of the obvious papillary microarchitecture helped to distinguish it from serous carcinoma. Histopathology confirmed the cytological 


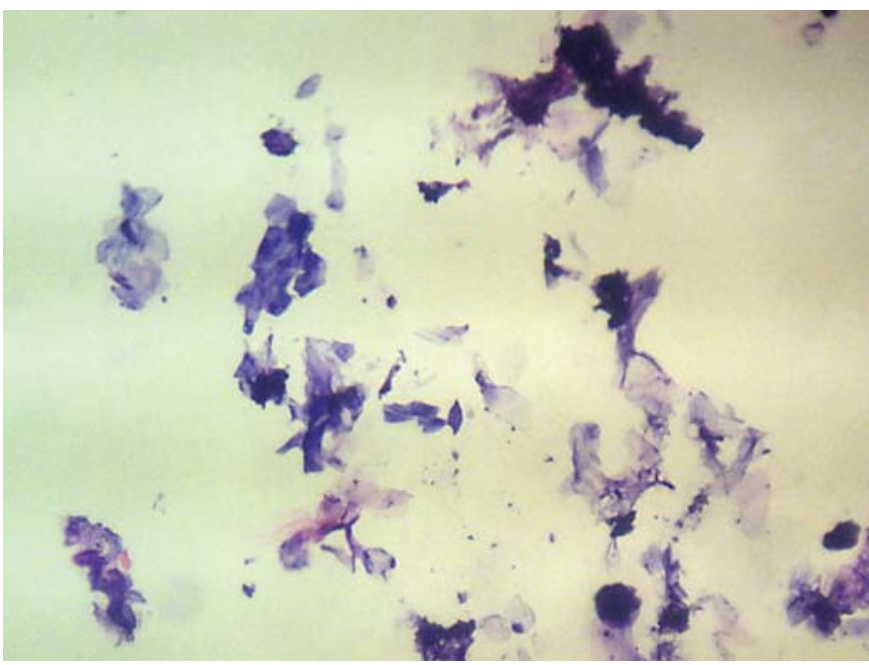

Fig. 5. Bening cystic teratoma: imprint smear shows anucleate squames, amorphous material and some inflammatory cells $(\mathrm{H} \& \mathrm{E}, \times 10)$.

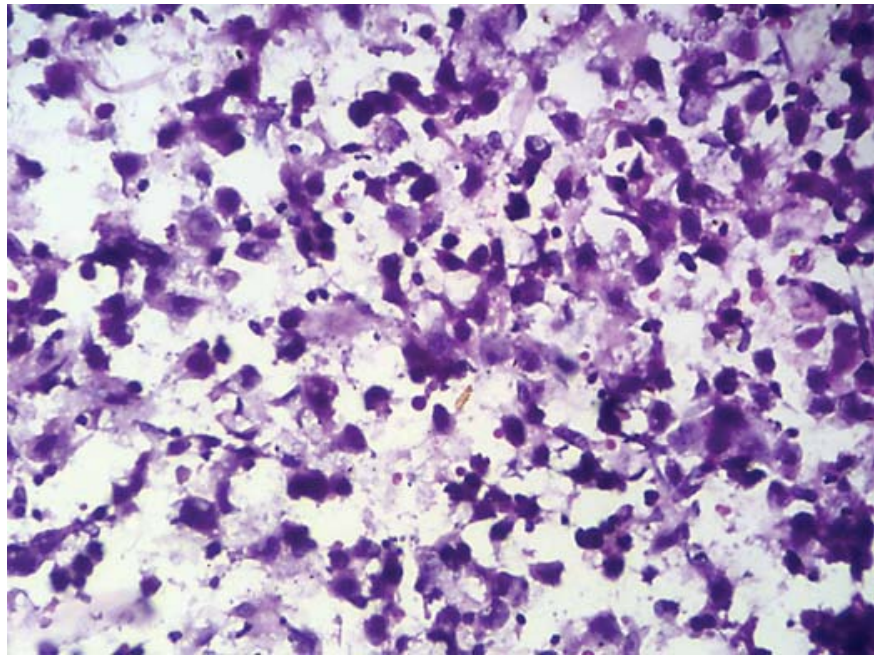

Fig. 6. Dysgerminoma: imprint smear shows poorly cohesive malignant cells with vesicular nuclei and prominent nucleoli with nuclear smudging in a tigroid background with fragile cytoplasm and lymphocytes $(\mathrm{H} \& \mathrm{E}, \times 40)$.

Table 1. Cytohistological correlation of Ovarian Neoplasm

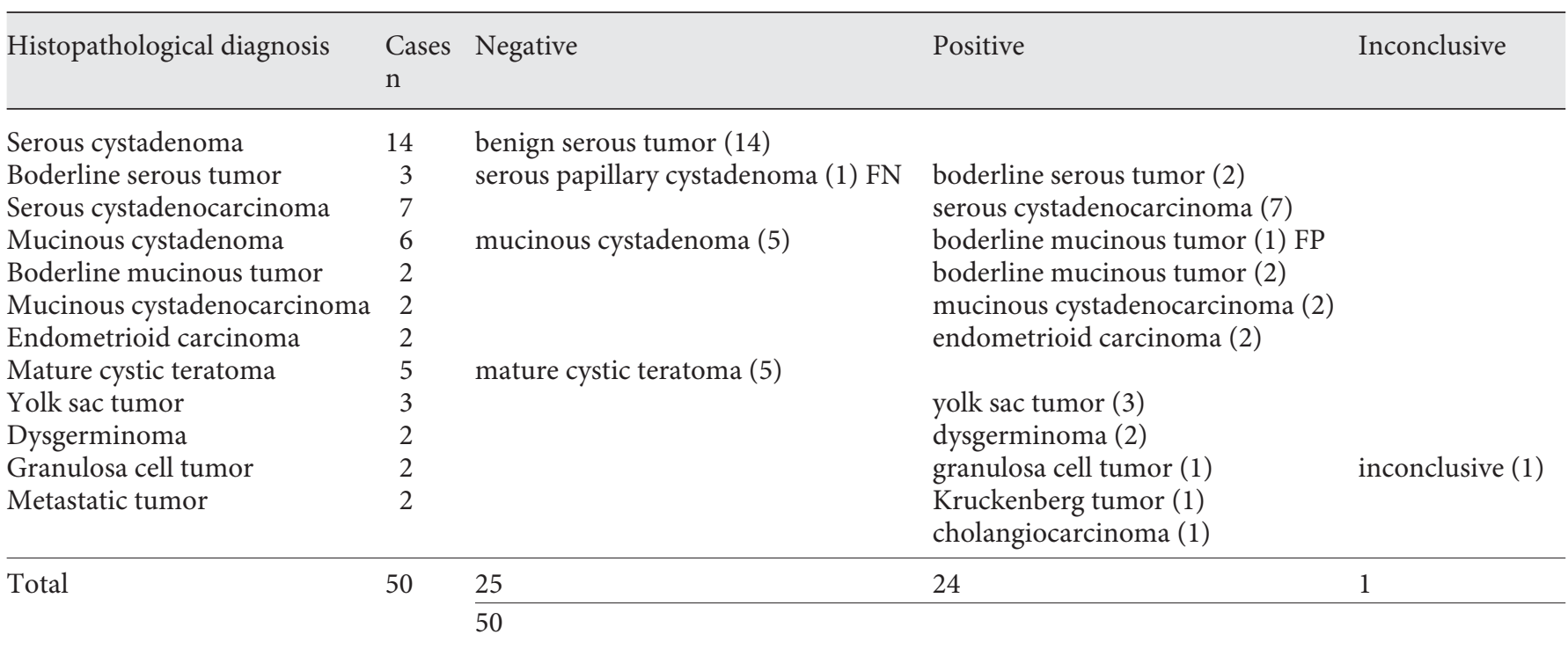

$\mathrm{FN}=$ False negative $; \mathrm{FP}=$ false positive

diagnosis and showed a complex tubulopapillary and cribriform architecture lined by stratified atypical nonmucinous epithelium with evidence of squamous differentiation.

There were 5 cases of benign cystic teratoma. Smears revealed anucleate squames, amorphous material, some inflammatory cells and red cells in the background (fig. 5). Histology evidenced a well-differentiated teratoma of the ovary. All cases of yolk sac tumor (3 cases) were accurately diagnosed. The tumors exhibited a large area of hemorrhage and necrosis. It was diagnosed based on the presence of loosely clustered glandular epithelial cells 
with prominent cytoplasmic vacuolation and occasional eosinophilic hyaline globules. Two cases of dysgerminoma were also correctly diagnosed. Smears displayed abundant cellularity with mainly dispersed cells with little tendency to clustering with large vesicular nuclei, and distinct nucleoli with abundant, fragile pale cytoplasm with vacuolation. The background was tigroid with nuclear smudging and lymphocytes (fig. 6). There were 2 cases of granulosa cell tumors which were accurately diagnosed by cytology and showed cell-rich smears with cells in loose aggregates and a tendency to microfollicular grouping with variable Call-Exner body. Cells have round-to-ovoid monomorphous nuclei with longitudinal grooves and fine granular chromatin. Cytoplasm is moderate-pale with a indistinct cell border. There were 2 cases of metastatic adenocarcinoma. Both were bilateral and solid, and on cytology showed pleomorphic epithelial cells with a glandular pattern in a necrotic background. Histopathologically, 1 was diagnosed as Krukenberg tumor due to the presence of signet ring cells, primarily located in the stomach, and the other as simple adenocarcinoma.

Except for 3 cases, all lesions were correctly identified. There was 1 case of borderline serous tumor, which was wrongly labeled as benign serous tumor (false negative), 1 case of mucinous cystadenoma, which was wrongly identified as borderline mucinous tumor (false positive) and 1 case of granulosa cell tumor, which was labeled as inconclusive due to sampling errors (table 1).

Final histopathogical diagnoses were: benign serous tumor in 14 cases, boderline serous tumor in 3 cases, serous cystadenocarcinoma in 7 cases, benign mucinous tumor in 6 cases, boderline mucinous tumor in 2 cases, mucinous cystadenocarcinoma in 2 cases, mature cystic teratoma in 5 cases, yolk sac tumor in 3 cases, dysgerminoma in 2 cases, granulosa cell tumor in 2 cases and metastatic tumor in 2 cases.

Comparing the diagnosis of cytological smears with histological sections, 47 of 50 cases were concordant. There were 23 true-positive, 1 false-positive, 24 true-negative and 1 false-negative and 1 inconclusive cases. For the purpose of statistical calculation, all borderline malignancies were included in the malignant group. Combining all the values, sensitivity, specificity and diagnostic accuracy were 95.8, 96.0 and $95.8 \%$, respectively; $2 \%$ of the cases were found to be inconclusive, which was quite satisfactory.

Average time taken to provide a diagnosis using IOC was found to be $<20 \mathrm{~min}$ from tissue removal.

\section{Discussion}

Intraoperative consultation is a very important aspect of surgical pathology that often guides the surgeon's hand. Traditionally, intraoperative pathological evaluation is based on frozen sections. In 1927, Dudgeon and Patrick [1] introduced cytology as a method of intraoperative pathological evaluation. Smears can be prepared directly from the lesion, rapidly stained and viewed under the microscope: diagnosis can be provided within minutes.

Ovarian neoplasms are a heterogeneous group of benign and malignant tumors of epithelial, stromal and germ cell origin. Most ovarian tumors cannot be easily distinguished from one another on the basis of their clinical or gross characteristics alone. Therefore, cytological interpretation of ovarian neoplasms is both interesting and challenging [7]. Fine-needle aspiration cytology in the preoperative investigation of the ovarian tumor has been discouraged since the puncture of a cystic carcinoma might cause intraperitoneal seeding. The intraoperative pathological consultation is indispensable in determining malignancy, and surgical staging and management for ovarian tumors because of the difficulty of their preoperative or pathological examination [8]. Frozen sections are the gold standard for the intraoperative diagnosis of malignant tumors, but they seem unsuitable for ovarian tumors that are large in size and have various pathological patterns. IOC has been adopted as the chief intraoperative pathological consultation at many centers for ovarian tumors; advantages of IOC are both its simplicity of producing many high-quality preparations and the rapid provision of results [9].

In ovarian lesions, IOC has been reported to have a diagnostic accuracy comparable to that of frozen sections [10]. There are several advantages of IOC over frozen sections which have been attested by different authors [1114]. They are: (1) rapidity of preparation which is not at the expense of accuracy; (2) simple and inexpensive method; (3) excellent preservation of cellular details without freezing artifacts; (4) no loss of tissue as with the cryostat; (5) possibility of identifying focal, macroscopically undetectable neoplastic lesions in large tissue fragments; (6) possibility of examining adipose, necrotic and calcified tissue; (7) diagnosis of malignancy when the tissue is limited in quality, and (8) avoidance of contamination and safe handling.

There were limitations of IOC in the diagnosis of tumors with low malignant potential and in mucinous tumors, which require histological architecture evaluation 
and adequate histological sampling [15]. Among the several cytological techniques applied to ovarian specimens, scrape cytology is often considered the most suitable [10, 16]. In developing countries like ours, where frozen sections are not always an option, cytology can reliably and independently be used as a method for intraoperative evaluation.

We used imprint, scrape or crush techniques for the preparation of smears, depending on the nature of the tissue received. Sometimes techniques were combined. Scrape was the most frequently used technique in the present study, which was in agreement with others $[15$, 17]. A variety of staining techniques have been used for IOC evaluation. We prefer the rapid $\mathrm{H} \& \mathrm{E}$ technique, which was our own modification of that used by Shidham et al. [12]. The results were excellent and good cytoplasmic as well nuclear details were obtained. Shidham et al. [12] also preferred the rapid $\mathrm{H} \& \mathrm{E}$ technique for IOC evaluation. They found $\mathrm{H} \& \mathrm{E}$ to be faster than $\mathrm{Pa}-$ panicolaou staining, and other polychromatic dyes were not useful in the differentiation of colors as obtained by $\mathrm{H} \& \mathrm{E}$. Long-term storage is another advantage which is not possible with Romanosky stains. Rao et al. [18] and Tushar et al. [19] also used H \& E in their studies of IOC of ovarian neoplasms.

The total number of ovarian tumors studied was 50 . These included 36 (72\%) celomic and 14 (28\%) non-celomic ovarian neoplasms. Of these, $20(40 \%)$ were benign, 5 (10\%) were borderline and 25 (50\%) were malignant. The age group varied from 17 to 68 years. Serous tumors were the most common $(24 / 50 ; 48 \%)$. This is comparable to the results of Pravakar and Maingi [20] who found a slightly lower incidence (32.7\%).

Of all ovarian neoplasms, 14 cases were serous cystadenomas $(14 / 50 ; 28 \%)$. A similar incidence was quoted by Koonings et al. [21], who found an incidence of $25 \%$. All of them were unilateral, cystic and contained clear fluid. Age ranged from 22 to 56 years. All 14 cases were correctly identified by IOC. Malignant serous tumors were noted in 7 cases $(7 / 50 ; 14 \%)$. Khunamornpong and Siriaunkgul [16] reported a similar incidence (11\%). No benign case was misdiagnosed as malignant or vice versa. In our study, 1 serous tumor of borderline malignant potential was identified incorrectly as benign serous tumor. Epithelial borderline tumors were difficult to distinguish from both benign and malignant epithelial tumors due to overlapping cytological features. In the absence of complex branching, nuclear pleomorphism and hyperchromasia, the overall morphology of cells closely resembled that of benign serous tumor [22]. Similar results were ob- tained by Khunamornpong and Siriaunkgul [16] in their study of borderline serous tumors with $50 \%$ correlation between IOC and final histopathological diagnosis.

Mucinous tumors formed the second most common epithelial tumor of the ovary (10/50;20\%): 5 of 6 cases of mucinous cystadenomas were identified correctly by IOC. One case of benign tumor was labeled as mucinous borderline tumor due to the presence of focal epithelial crowding and increased $\mathrm{N}: \mathrm{C}$ ratio but minimal nuclear atypia. Although nuclear crowding may suggest atypical proliferation [16], mucinous borderline tumors should have nuclear atypia in a significant number of cells. A $10 \%$ minimum involvement of the material, comparable to histologic criteria [17], may be applied. Two boderline mucinous tumors were identified correctly by IOC with nuclear atypia characterized by increased nuclear irregularity or lobulation, nuclear enlargement with variable degree of chromatin clumping and increased N:C ratio. Subsequent histopathology revealed no stromal invasion. All cases of mucinous adenocarcinomas were correctly identified by IOC.

Endometrioid carcinomas have overlapping features with serous carcinomas, but in our study 2 cases of endometrioid carcinoma were identified correctly with more elongated nuclear shape than serous carcinoma. Rosettelike or glandular arrangements were focally present. Among the germ cell tumors, the most common type in our study was mature cystic teratoma followed by 3 cases of yolk sac tumor and 2 cases of dysgerminoma, which were correctly identified by IOC.

Khunamornpong and Siriaunkgul [16] also found an accuracy of $100 \%$ in the diagnosis of germ cell tumors. One case of granulosa cell tumor was labeled as inconclusive due to inadequate sampling; another was identified correctly with loose sheets and groups of small, uniform, round cells with scant cytoplasm. Rosette-like arrangement was frequently seen. Many pink globules of varying size were present within the cell groups and in the background. These globules correlated with material in CallExner bodies. In metastatic cancers, IOC was helpful in identifying the metastatic nature in correlation with clinical and gross findings. A case of Krukenberg tumor was recognized with its characteristic cytology; another case was recognized as biliary tract cancer based on the previously recorded history of primary malignancy.

Sensitivity, specificity and overall diagnostic accuracy were $95.8,96.0$ and $95.8 \%$, respectively. In $2 \%$ of the cases, data were inconclusive. Our findings were in accordance with those of other workers. In a study by Kjellgren et al. [23] on fine-needle aspiration biopsy of ovarian carcino- 
ma, sensitivity was $90 \%$, specificity $85 \%$ and diagnostic accuracy $93-95 \%$. The results were better than in a previous report by Nagai et al. [10] with a sensitivity and specificity to discriminate malignant/borderline from benign lesions of 89.5 and $90.3 \%$, respectively, and a diagnostic accuracy of $83.6 \%$. In a study involving aspiration cytology of neoplastic and non-neoplastic cysts by Ganjei et al. [24], sensitivity was $75 \%$, specificity $100 \%$ and overall accuracy $96 \%$ in malignant cysts. Since the facility of frozen section examination is not available at our institution, a comparison with IOC was not possible, but a recently published meta-analysis of 18 studies comparing frozensection diagnosis of ovarian pathology with the final histopathology showed that its sensitivity to detect benign and malignant lesions varies from 65 to 97 and 71 to $100 \%$, respectively, and specificity from 97 to 100 and 98.3 to $100 \%$, respectively [25]. Our overall sensitivity and specificity ( 95.8 and $96.0 \%$, respectively) were in accordance with the results of the above-mentioned metaanalysis.
We are convinced by the utility of IOC and recommend its use for the diagnosis of ovarian lesions, especially in developing countries like ours, where frozen sections are often not available. It can act as a good complement to histopathology and can be of benefit for rapid preliminary diagnosis and surgical management planning. It has a high diagnostic accuracy which can be further increased if the diagnosis is extended to and confirmed by gross and radiologic findings. Although there are limitations of IOC in cases where the diagnosis requires architectural assessment or extensive sampling, IOC helps to distinguish benign lesions from frankly malignant tumors in most cases in our experience. Specific histological subtypes can also be predicted in the majority of cases. It is helpful especially in young patients who need conservative surgery in order to preserve fertility. It does not alter the quality of the biopsy specimen [24].

To conclude, IOC is extremely useful and provides a simple, rapid and inexpensive adjunctive technique for the intraoperative consultation of ovarian lesion.

\section{References}

$\checkmark 1$ Dudgeon LS, Patrick CV: A new method for rapid microscopical diagnosis of tumors: with an account of 200 cases so examined. $\mathrm{Br}$ J Surg 1927;15:250-261.

$\checkmark 2$ Suen KC, Wood WS, Syed AA, Quenville NF, Clement PB: Role of imprint cytology in intraoperative diagnosis: values and limitations. J Clin Pathol 1978;31:328-337.

$\checkmark 3$ Kontozoglou TE, Cramer HM: The advantages of intraoperative cytology. Analysis of 215 smears and reviews of literature. Acta Cytol 1991;35:154-164.

4 Mair S, Lash RH, Suskin D, Mendelsohn G: Intraoperative surgical specimen evaluation. Frozen section analysis, cytological examination or both? A comparative study of 206 cases. Am J Clin Pathol 1991;96:8-14.

$\checkmark 5$ Clarke MR, Landreneau RJ, Borochovit D: Intaoperative imprint cytology for evaluation of mediastinal lymphadenapathy. Ann Thorac Surg 1994;57:1206-1210.

6 Rahman K, Siddiqui FA, Zaheer S, Sherwani MKA, Shahid M, Sherwani RK: Intraoperative cytology - role in bone lesion. Diagn Cytopathol 2010;38:639-644.

7 Eltabbakh GH, Trask CE: Scrape cytology for intraoperative evaluation of lymph nodes in gynecological cancer. Obstet Gynecol 2000;95:67-71.

8 Bonfiglio TA, Yenser SE: Gynaecological Cytology. Philadelphia, Lippincott-Raven, 1997, pp 157-164.
9 O’Hanlan KA: Principles of surgical management of ovarian carcinomas. Pathology 1993;1:477-489.

10 Nagai Y, Tanaka N, Horiushi F, Okhi S, Seki K, Sekia S: Diagnostic accuracy of intraoperative imprint cytology in ovarian epithelial tumors. Int J Gynecol Obstet 2001;72: 159-164.

11 Michael CW, Lawrence WD, Bedrossian CWM: Intraoperative consultation in ovarian lesions: a comparison between cytology and frozen section. Diagn Cytopathol 1996; 15:387-394.

12 Shidham VB, Dravid NV, Kher AV: Role of scrape cytology in intraoperative diagnosis. Values and limitations. Acta Cytol 1984;28: 477-482.

13 Orki A, Tezel C, Kosar A, Ersev AA, Dudu C, Arman B: Feasibility of imprint cytology for evaluation of mediastinal lymph nodes in lung cancers. Jpn J Clin Oncol 2006;36:7679.

14 Ferit T, Aylar P, Buelent S, et al: Using imprint and frozen sections in determining the surgical strategies for thyroid pathologies. Endocr Regul 2001;35:71-74.

15 Cabay RJ, David O, Cimbaluk D, Gould V: Cytologic features of primary chondroid tumors of bone in crush preparations. Diagn Cytopathol 2008;36:758-761.

16 Khunamornpong S, Siriaunkgul S: Scrape cytology of the ovaries: potential role in intraoperative consultation of ovarian lesions. Diagn Cytopathol 2003;28:250-257.
17 Philips J: Intraoperative cytological diagnosis; in Russell P, Farnsworth A (eds): Surgical Pathology of the Ovaries, ed 2. New York, Churchill Livingstone, 1997, pp 643-656.

18 Rao S, Sadiya N, Joseph LD, Rajendiran S: Role of scrape cytology in ovarian neoplasms. J Cytol 2009;26:26-29.

19 Tushar K, Asaranti K, Mohapatra PC: Intraoperative cytology of ovarian tumors. J Obstet Gynecol India 2005;55:345-349.

20 Prabhakar BR, Maingi K: Ovarian tumours prevalence in Punjab. Indian J Pathol Microbiol 1989;32:276-281.

21 Koonings PP, Campbell K, Mishell DR, Grimes DA: Relative frequency of primary ovarian neoplasms: a 10-year review. Obstet Gynecol 1989;74:921-926.

22 Russell P: Surface epithelial-stromal tumors of the ovary; in Kurman RJ (ed): Blaustein's Pathology of the Female Genital Tract, ed 4. New York, Springer, 1994, pp 705-782.

23 Kjellgren O, Angström T, Bergman F, Wiklund DE: Fine needle aspiration biopsy in diagnosis and classification of ovarian carcinoma. Cancer 1971;28:967-976.

24 Ganjei P, Dickinson B, Harrison T, Nassiri M, Lu Y: Aspiration cytology of neoplastic and non-neoplastic ovarian cysts: is it accurate? Int J Gynecol Pathol 1996;15:94-101.

-25 Geomini P, Bremer G, Kruitwagen R, Mol BW: Diagnostic accuracy of frozen section diagnosis of the adnexal mass: a metaanalysis. Gynecol Oncol 2005;96:1-9. 